\title{
0 cérebro midiatizado: imagens do corpo e da vida na cultura contemporânea
}

\section{Resumo}

O cérebro aparece atualmente, nas revistas dos mais diferentes gêneros de divulgação, destacando-se visualmente nas bancas de jornais. No palco privilegiado do cenário midiático impresso, este órgão do corpo humano é apresentado como o protagonista da vida na cultura contemporânea. Disputa espaço nas vitrines com fotos de astros da mídia, de modelos afamados em novas coleções de vestuário, competindo com o desfile dos corpos sarados e com os exercícios físicos mais eficazes para entrar "em forma". Neste artigo discutimos como a produção discursiva biocientífica, especialmente das Biociências, torna-se, através de revistas de divulgação, um dispositivo produtor de retórica relativa à normatização da saúde. Neste contexto, o cérebro se eleva como o órgão principal do ser humano.

Palavras-chave: Divulgação Científica. Imaginário. Biociências. Cérebro.

\footnotetext{
* Pontifícia Universidade Católica do Rio Grande do Sul, Brasil

** Universidade Federal do Rio Grande do Sul, Brasil
} 


\title{
The mediatized brain: images of body and life in contemporary culture
}

\begin{abstract}
The brain appears today, in magazines aimed at the most diverse segments of science popularization, standing out visually in newsstands. On the privileged stage of the printed media domain, this organ of the human body is presented as the protagonist of life in contemporary culture. It competes for space in display cases against photos of media stars and famous models in new clothing collections, racing with the parade of healthy bodies and with the most effective physical exercises to get in shape. In this article, we discuss how the scientific discursive production, particularly that of the Biosciences, becomes, through magazines, a device that produces a rhetoric on health regulation. In this context, the brain arises as the main organ of the human being.
\end{abstract}

Keywords: Science communication. Imaginary. Life sciences. Brain.

\section{Resumen}

El cerebro aparece hoy en revistas de los diferentes géneros de divulgación, destacándose visualmente en los quioscos. En el escenario privilegiado del panorama de los medios impresos, este órgano del cuerpo humano se presenta como el protagonista de la vida en la cultura contemporánea. Él disputa espacio con las estrellas de la media, con fotos de modelos famosos en nuevas colecciones de moda y compite con el desfile de cuerpos sanos y con los ejercicios más eficaces para estar "en forma". En este artículo, se discute cómo la producción discursiva científica, especialmente de las Biociencias, se convierte, a través de revistas de divulgación, en un recurso retórico de regulación de la salud. En este contexto, el cerebro se eleva como órgano principal del ser humano.

Palabras clave: Divulgación científica. Imaginario social. Ciencias de la vida. Cerebro. 


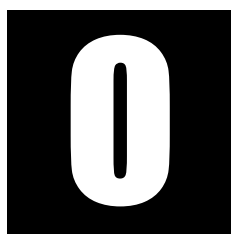

avanço das Neurociências ampliou o estudo do cérebro e de sua complexidade, de seu desempenho no funcionamento do corpo. Este órgão, objeto de análise neste estudo, ganha um papel importante na vida e no viver, tornando-se objeto constante de investigação nas Biociências ${ }^{1}$. A morte clínica passou a ser atestada nos hospitais somente quando o eletroencefalograma se estabiliza, ainda que o corpo funcione por meio de máquinas. Qualquer outro órgão está sujeito a transplante; o cérebro, até o momento, não.

Ao mesmo tempo, o cérebro desempenha funções importantes em todo o organismo, sejam elas neuronais ou mentais ${ }^{2}$. Essa credencial, que habilita o cérebro a ter tanto destaque na mídia, o eleva a uma posição que, em outros tempos, seria ocupada pelo coração ou pelo pulmão, tidos nos séculos anteriores como os "órgãos da vida". Mas não é apenas por sua dimensão biológica que o cérebro ganhou todo esse foco. Nos debates sobre a maximização da vida, ele figura como esperança na aposta da imortalidade humana, através de técnicas avançadas como a produção de um "cérebro externo" ou pela "criogênia" - o congelamento do corpo - visando a prolongar a vida biológica (Ortega, 2009).

Além disso, com a explosão contemporânea da tecnociência, da medicalização intensiva e das técnicas para otimização do desempenho biológico, o cérebro responde, cada vez mais, por tudo o que outrora se atribuía ao sujeito, à pessoa, ao indivíduo. Há um avanço significativo das

\footnotetext{
${ }^{1}$ Como exemplo, há pesquisas que utilizam neuroimagens para decifrar não somente doenças com Alzheimer e Parkinson, mas também a natureza das escolhas sexuais, gostos e características pessoais (Ortega; Zorzanelli, 2010, p. 77).

2 Faz-se necessária aqui a diferenciação entre cérebro e mente. Cérebro é o órgão fundamental para o sistema nervoso que oferece suporte biológico para a coleta de informações do ambiente e para a produção de respostas adequadas, bem como pela coordenação ativa do sistema motor-muscular. Já a mente é o conjunto de funções superiores do cérebro, como a memória, a inteligência, a emoção e o pensamento, cujo funcionamento daria particularidade aos indivíduos (Ortega; Zorzanelli, 2010, p. 105).
} 
tecnologias neurocientíficas através de exames como a ressonância magnética, que põe em relevo as imagens, assim como a busca de tecnologias de localização de processos cognitivos e emocionais (Hagner; Borck, 2001 apud Ortega, 2008).

A revista Mente e Cérebro (MC), integrante do grupo Scientific American, chamou nossa atenção por ser representante da divulgação científica (Luz et al., 2013a), gênero que apresenta resultados de pesquisas diretamente para o público leigo. Nesta publicação, neurociências, psicanálise, e evidentemente, o cérebro e a mente, são destaques como notícia ${ }^{3}$.

A repetição continuada de padrões de imagens e palavras referentes ao cérebro nas chamadas de capa - em cruzamento de elementos gráficos e verbais - é, a nosso ver, um indício da recorrência de práticas retóricas na divulgação científica, ao fazer emergir figuras, analogias, metáforas ou clichês que, embora sutis, tornam-se potentes e incisivos em sua função de convencimento. É esta função de convencimento que configura nosso objetivo de estudo e objeto de análise.

\section{Imagens de corpos na contemporaneidade}

A oferta de conteúdos de saúde no imaginário midiático é consoante com o tratamento que a sociedade contemporânea ocidental dá aos corpos, enaltecendo-os como palco de performances e designs efêmeros, que encobrem um desprezo factual por sua realidade e suas imperfeições naturais. Um corpo fora desses padrões de controle é encarado por quem compartilha do imaginário dominante como falha de caráter ou deficiên-

\footnotetext{
${ }^{3}$ Nas capas e artigos internos de MC, fica nitidamente marcada a presença de pesquisadores e cientistas renomados, que assinam seus textos. São abordados temas sobre neurociências e sobre psicanálise em várias situações como o adoecimento e suas causas, bem como distúrbios psicoemocionais, ou ainda, as dicas para a maximização dos recursos neuronais e mentais. A psicologia e a psicanálise também têm espaço, embora apareçam em vários momentos relacionadas a patologias, geralmente de origem neurológica.
} 
cia no manejo de si próprio, levando a um processo de autorreprovação, pelo desvio das regras de autocontrole. Entretanto, há meios socialmente admitidos de se isentar da responsabilidade pelas "faltas" (Sabino, 2012; Foucault, 2000; Costa, 2004 apud Ortega; Zorzanelli, 2010, p. 96).

A racionalidade científica vem ganhando força em relação ao imaginário social. Significados e sentidos são constantemente invadidos e "formatados" por imagens, representações e modos de sentir veiculados pelos saberes científicos, suas concepções e ideologias (Luz et al., 2013b, p. 241).

O corpo, representado como máquina possante, passou a ser valorizado como capital a ser gerido, no qual devemos investir, merecendo destaque recorrente na mídia, que passou a acompanhar, com frequência e abrangência crescentes, as pesquisas geradas no campo das Biociências. Ao mesmo tempo, o corpo biológico é desconsiderado em sua organicidade e materialidade (Sabino, 2012).

Esses fluxos de informações seguem, com frequência, estratégias informacionais de poder, especialmente poder simbólico (Bourdieu, 2010) e biopoder ${ }^{4}$, estabelecidos a partir do lugar da fala do emissor da informação. Nessa perspectiva, constituem-se, por meio do discurso e da imagem, num dispositivo discursivo em um tempo e espaço históricos específicos. Atuam na imposição ou legitimação da informação a partir da perspectiva institucional das organizações e no sistema institucional de saúde como um todo (Moraes, 2008).

O saber hegemônico normatizador biocientífico impõe regras e modelos de comportamentos e se constitui em imaginário social, ganhando materialidade por meio de representações e práticas reiteradas. Foucault

\footnotetext{
4 "As relações de poder teriam um funcionamento positivo cuja obrigação principal seria a incitação à produção de formas de relação consigo mesmo por meio de um controle minucioso dos gestos, do corpo do espaço e do tempo. Vemos aí se formar uma concepção produtiva do poder de um afastamento de sua concepção jurídica - mais do que reprimir o poder se exerceria pela objetivação da realidade, isto é, pela criação de modo de se relacionar consigo e com o mundo" (Foucault, 2000, p. 69).
} 
(2000) afirma que o poder não está situado em algum ponto específico da estrutura social e ninguém é seu titular. Existindo poder, ele se exercerá. O saber é, talvez, a forma mais efetiva de poder.

Quando falamos em saúde e vida, sob a perspectiva da Saúde Coletiva, não estamos tratando só do adoecer e do morrer, mas dos mais diferentes momentos da vida, e não apenas vida biológica ${ }^{5}$. Como bem sintetizam Akerman e Feuerwerker (2012), saúde é "um produto da história, da cultura, da organização social e envolve as condições de vida e trabalho" (p. 172). Está também relacionada ao espaço onde vivem as pessoas, onde se alimentam, bem como expressam suas subjetividades, valores e relações afetivas.

\section{O cérebro das neurociências}

As neurociências, elemento importante no nosso universo de pesquisa, surgiram como disciplina há cerca de quarenta anos, a partir das experiências de psicólogos experimentais e neurocientistas. Como campo de conhecimento, ganharam espaço progressivamente mais significativo na pauta das revistas, programas de televisão e reportagens de jornais. Podem ser caracterizadas como fruto da expansão da cultura somática, do desenvolvimento das neuroimagens e da perspectiva científica de tratar o cérebro como o órgão definidor da identidade, como o "lugar" da "alma" (Ortega; Zorzanelli, 2010).

No entanto, o cérebro não ganhou protagonismo apenas por seu papel nas funções neuronais ou mesmo mentais. Vem se destacando nos debates

\footnotetext{
5 Em muitos momentos, a Saúde Coletiva se posiciona no intuito de promover perspectivas que levem em consideração as dimensões sócio-humanas, rompendo com a imagem do hospital como único espaço de cuidado em saúde (Foucault, 2000), no qual apenas a figura dos profissionais de saúde, em especial médicos, são reconhecidos como detentores exclusivos do saber sobre a vida e a saúde.
} 
sobre a maximização da vida e figura como esperança na aposta da imortalidade humana (Ortega, 2009). Há pesquisas que procuram desenvolver as técnicas de neuroimagens para decifrar não somente doenças como Alzheimer e Parkinson, mas também a natureza das nossas escolhas sexuais nossos gostos e nossas características pessoais (Ortega; Zorzanelli, 2010).

O imageamento do cérebro começou nas décadas de 1950 e 1960, em pesquisas com o uso de scans por tomografia computadorizada. No final dos anos 1970, a tecnologia passou a ser incorporada à clínica. Antes disso, um dos principais métodos para estudar a conexão entre cérebro e comportamento era indireto, pelo exame de cérebros abertos para avaliar como as lesões afetam a performance diária (idem, p. 49).

A ressonância magnética funcional tornou possível acompanhar, em tempo real, a ativação cerebral, ou seja, o deslocamento do sangue para cada área do cérebro. Uma mudança no fluxo sanguíneo poderia refletir uma atividade neural específica em áreas do cérebro caracterizadas por desempenhar determinadas funções. Com isso, supõe-se que essas áreas estejam diretamente implicadas nas funções executadas (idem, p. 50).

Essa abordagem fortalece o "mito da transparência do corpo" (idem, p. 50), pelo qual o cérebro seria acessado internamente por imagens. Esta, no entanto, não é uma atividade sem consequências. A cada novo instrumento que produz quadros mais precisos das patologias, o ideal de domínio sobre o corpo vai sendo consolidado como convenção social. O corpo, desvelado por essas tecnologias, torna-se ainda mais complexo - e, por isso, menos acessível: "quanto mais se vê por meio de lentes e parâmetros avaliados mais complicada a informação visual alcançada e o próprio objeto visto" (idem, p. 19).

Há os que defendem o processo de cerebralização dos comportamentos, com desdobramentos fora dos campos filosóficos, na articulação das neurociências com as ciências humanas, que se reformulam à luz do co- 
nhecimento sobre o cérebro, como a neuropsicanálise, neuroeducação ${ }^{6}$, a neuroteologia, a neuroética, etc (Kickhöfel, 2014; Ortega; Zorzanelli, 2010).

\section{O cérebro nas capas de revistas}

Um dos traços preliminares que constatamos nas observações de campo nas capas das revistas nas bancas foi a recorrência ao uso de elementos gráficos e textuais que remetem ao mecanismo ${ }^{7}$, quando se abordam questões sobre o corpo e sobre a vida (Luz, 2004). O mecanicismo gera uma metáfora para apreender e se relacionar com o mundo a partir da metáfora da máquina, na qual a natureza e o mundo, e por consequência, o corpo humano, são comparados a engenhos (idem). Esses aparatos funcionam com suas peças e mecanismos regulados, cujas leis podem ser expostas, pela razão e pela experiência, preferencialmente em linguagem formal - matemática -, ou seja, descritos sob os critérios rigorosos do método científico ${ }^{8}$.

São imagens e metáforas que trabalham diversos aspectos do corpo e da natureza como "engenho", "máquina", "autômato", cujas peças são expostas, funcionando com seus mecanismos regulados, e cujas leis

\footnotetext{
${ }^{6}$ Conhecimentos neurocientíficos utilizados para aperfeiçoar métodos pedagógicos e corrigir limitações na aquisição de conteúdos.

7 O racionalismo mecanicista do século XVIII partilha uma cosmovisão banhada no imaginário da modernidade clássica (séc. XVII), sobre o mundo e a matéria, baseadas em representações dessas categorias em termos de "engenho" ou "máquina", decorrentes das atividades de produção social dos séculos XVI e XVII. Foram as construções de máquinas e automatismos do homem do período barroco - que estão, segundo Luz, na origem das metáforas mecânicas que, por sua vez, deram origem a concepções filosóficas mecanicistas no século XVII e teorias científicas do fim do século XVIII e parte do séc. XIX. (Luz, 2004)

8 As disciplinas avançadas como física, química, astronomia, e até da biologia, já não levam tão a sério as metáforas mecanicistas da racionalidade moderna, como a de imaginar os seres orgânicos e inorgânicos como máquinas. Porém, há uma tendência metodológica das disciplinas das ciências mais próximas da vida humana, como a Biologia e a Medicina, de decompor o objeto, no caso o corpo biológico, em elementos, comparando por uma operação analítica, esses elementos entre si, ordenando-os numa hierarquia recomposta racionalmente (Luz, 2004).
} 
podem ser enunciadas a partir das atividades da razão e da experiência, preferencialmente em linguagem formal, isto é, estatístico-matemática (Luz, 2004).

A medicina ocidental contemporânea incorporou esses processos, elencando a medicalização como um fio condutor e indutor de suas práticas e saberes, muitas vezes caracterizadas por ações preventivas ou curativas que despersonalizam o sujeito, face ao seu caráter normativo, através da ênfase na doença, desconsiderando seus aspectos subjetivos e sociais (Pinheiro; Mattos, 2007). Essa lógica tem influência na oferta e na demanda de serviços de saúde nos últimos tempos ${ }^{9}$.

Para manter esse imaginário empoderado, há ainda recursos importantes como o medo e o risco ${ }^{10}$, reforçados pela dependência e submissão aos rigores das Biociências (Foucault, 2000; Castiel, 2003; Bauman, 2001). Somos bombardeados constantemente por alertas sobre doenças contagiosas e epidemias que interessam à coletividade mais que ao próprio indivíduo, uma vez que a sociedade é quem "paga" por esse direito imprescindível - a saúde (Mello, 2010). O dispositivo de produção de verdade científica adquire, estrategicamente, a prerrogativa de definir comportamentos e modos de viver "saudáveis", exercendo poder irrestrito sobre os corpos (Foucault, 2000).

\footnotetext{
9 Isoladamente, o paradigma biomédico é insuficiente para compreender e abordar o processo saúde-doença, porque esse modelo ainda vigora no "imaginário de saúde como prestação de serviços altamente tecnificados, com usuários tomados por seus padrões biológicos" (Ceccim et al., 2008/2009, p. 447-8), onde o hospital ocuparia o topo de uma hierarquia qualitativa de trabalho na saúde, reafirmando a importância do conhecimento científico como normatizador das práticas e relações sociais na sociedade contemporânea (Foucault, 2000).

${ }^{10}$ De forma preliminar, já percebemos, em trabalho de campo, que muitas orientações recomendadas pelas reportagens, infundem um temor difuso de que algum mal à saúde - ou à vida -, suceda, em caso de não-seguimento de tais práticas, recomendando medidas normativas que prometem a diminuição dos riscos potenciais (Luz et al., 2013a; Foucault, 2000; Luz, 2013; Castiel, 2003; Bauman, 2001).
} 
Por outro lado, como argumentação em favor dessas proposições sobre a vida, as descobertas neurocientíficas acentuam um potencial de esperança para cura e tratamento de várias doenças, bem como a possibilidade de aprimorar a saúde, tornando o corpo passível de produzir valor econômico (Ortega; Zorzanelli, 2010, p. 92). Afinal, segundo esses princípios, há uma ênfase pela autonomia e autogestão da vida, que reforçam a pressão pelo êxito no trabalho para adultos e bons resultados escolares para crianças.

\section{Retórica e representações sociais}

No compartilhar de imagens e textos, são reforçadas representações sociais que difundem esquemas mentais coletivos e individuais, construídas a partir de relações sociais vigentes, segundo Luz (1998). Condicionam, dessa forma, padrões de atitudes, sentimentos, ações e interações sociais. Essas representações são partilhadas pelos sujeitos humanos, o que implica num aspecto objetivo e num aspecto subjetivo, isto é, de absorção, interiorização e elaboração pelos sujeitos nas mais diversas situações de vida. São também vividas por grupos, adquirindo uma dimensão objetiva, isto é, de natureza coletiva, portanto, cultural, sujeita à historicidade.

Spink (1996) afirma que as representações sociais cobrem toda a gama dos domínios do agir, do pensar e do sentir, intercomunicando os planos psíquico e social dos sujeitos, criando laços estáveis. Numa teia simbólica, tecem o conjunto de regras sociais estabelecidas, na sua diversidade e nas suas contradições. Não há univocidade de sentido nem homogeneidade de intenções e significados nesse conjunto de representações em uma cultura dada:

Uma certa ambiguidade de imagens e sentidos permite, pelo contrário, o consentimento e a permanência em um número maior de membros da sociedade desta matéria- 
-prima da coesão social que são as representações sociais. Além disso, as representações nunca se apresentam isoladas, tendendo a se associar, formando corpo, isto é, constituindo gestalts simbólicas que tendem, por sua vez, a se transformar em concepções que se ancoram e solidificam nos diversos grupos e classes sociais, constituindo-se em verdadeiros sensos comuns estáveis, de difícil transformação histórica (Luz, 1998, p. 8).

O imaginário social constitui uma dimensão real da sociedade, em nível simbólico, que mobiliza de maneira efetiva as ações humanas e legitima coletivamente essas ações. Durand (1993) define imaginário ${ }^{11}$ como um conjunto de imagens e relações de imagens que constituem o capital pensado do homo sapiens pela simbolização (Durand, 1993; Silva, 2012). Já Maffesoli (2001) afirma que o imaginário se constitui pela ideia de fazer parte de algo, de partilhar uma filosofia de vida, uma linguagem, uma atmosfera, uma ideia de mundo, uma visão das coisas, na encruzilhada do racional e do não-racional. É também um estado de espírito de grupo ${ }^{12}$, de uma comunidade, promovendo vínculos - um cimento social (Maffesoli, 2001).

Nesse contexto, em que o mundo contemporâneo atribui valor considerável ao universo simbólico em suas relações com a prática cotidiana, o ideal de saúde e vida ganhou uma importância social aliada à busca incessante de máxima eficiência biológica e da felicidade plena a todo instante. Esse ideal se consolida através de representações sociais que

11 O imaginário de que falamos não é o oposto do real, algo fantasioso ou imaginativo, mas sim o imaginário que está no âmbito das ideias, como introjeção do real, processando a aceitação inconsciente, ou quase, de um modo de ser compartilhado pelos outros. Diferente do imaginado - projeção irreal que poderá se tornar real -, o imaginário emana do real, estrutura-se como ideal e retorna ao real como elemento propulsor (Silva, 2006).

12 “...o grupo, na concepção de Maffesoli, é tomado como um indivíduo de múltiplas cabeças, um ente polissêmico, fraturado, mas de vontade praticamente única. (...) ... o imaginário, tribal, retira o indivíduo da solidão para inseri-lo numa atmosfera de partilha. Assim, ao produzir sentido grupal, o imaginário só poderia ser a negação do indivíduo pela sua assimilação num todo aconchegante e orientador. A autonomia individual, porém, não desaparece, pois o imaginário não é um determinismo." (Silva, 2006, p. 11-2). 
reforçam a crença em uma utopia que promete a saúde perfeita (Sfez, 1996). O imaginário sobre as Biociências tende, assim, a constituir-se em um conjunto complexamente sistematizado e híbrido de imagens, representações, palavras e ações construídas e socialmente partilhadas (Foucault, 1997; Weber, 2004; Merton, 1973; Bourdieu, 2010; 2004; Luz et al., 2013b; Durand, 1993).

\section{Caminho metodológico de análise}

As capas das revistas impressas, com suas imagens e legendas, assumem um caráter sugestivo de compra e leitura do exemplar do periódi$\mathrm{Co}^{13}$. Constituem-se em um conjunto de signos que nos sugerem o que devemos ler, empregando expressões textuais e elementos gráficos apelativos nas chamadas, em conjunto com as fotos estampadas, que fazem menção ao núcleo do tema central do artigo no interior da revista, com forte sugestão de interesse ao leitor (Luz et al., 2013a).

Propusemos que a interpretação dessa retórica buscasse um procedimento metodológico no qual a questão da veracidade do conteúdo discursivo da mensagem (Medrado, 2000), isto é, sua "verdade" ou "inverdade" não fosse o objetivo da análise. Entendemos que as análises clássicas de conteúdo não respondem às questões relativas à retórica, levantadas pelo projeto a partir de 2012 (Luz et al., 2013b), de que este texto é fruto, e desenvolvidas em artigo publicado em 2013 (Luz et al., 2013a).

Entendemos que não são apenas as palavras que direcionam a aproximação com os temas propostos em cada edição. As imagens estampadas,

\footnotetext{
${ }^{13}$ Ressaltamos que a opção de concentrar as análises nas capas é reforçada pelo consenso estabelecido no campo da Comunicação Social de que o público em geral decide-se a comprar as publicações em função do interesse despertado pelo que é sugerido nas chamadas (Medrado, 2000). De fato, durante o campo realizado para o referido projeto, pôde-se observar que os temas escolhidos, quando bem trabalhados em sua apresentação gráfica, mobilizam a escolha do cliente conforme relato de proprietários de bancas visitadas (Luz et al., 2013a).
} 
reforçadas pelas palavras que as acompanham, contribuem para criar um processo afirmativo de poder simbólico, que induz convencimento no leitor. É essa simbiose imagem/palavra que reforça no mesmo que a mensagem que está sendo transmitida é digna de crédito e deve ser seguida pelo consumidor (Bourdieu, 2010; Luz et al., 2013a). Todo esse processo discursivo carreia um constante convencimento do leitor, nem sempre consciente, que denominamos em nosso estudo de retórica de vida e saúde.

Sugerimos, consequentemente, que a matéria-prima simbólica, ao ser processada por diferentes dispositivos de produção discursiva, assume distintas configurações com diferentes finalidades.

A partir da observação das imagens e textos relacionados ao cérebro nas capas, coletamos a matéria-prima da análise, constituída por elementos textuais (verbais e não-verbais, enunciados) e por elementos simbólicos (signos, significantes, símbolos) associados. Estes, usados como estratégia de convencimento no processo de divulgação científica, atuam como dispositivo produtor de verdades, porém num registro retórico de mensagens.

\section{Interpretação das revistas}

Tomando o universo simbólico das capas da Revista Mente e Cérebro coletamos os dados recorrentes sobre elementos gráficos e textuais da manchete principal referentes ao cérebro, apreendida pelo título de maior destaque, seu complemento em texto e a imagem que ilustra a capa.

A partir dos dados elencados, foram observados elementos simbólicos recorrentes nas capas da publicação no período de quatro anos (20122015). Foram coletadas mensagens que emergiram dos elementos simbólicos (palavra/imagem-chaves) considerados importantes para a análise.

Como primeiro exemplo de análise, destacamos a edição 236 da Revista Mente e Cérebro, de setembro de 2012, com o título A ciência a 
um passo de ler pensamentos: Num futuro próximo, as pessoas poderão se comunicar apenas por meio da mente (figura 1).

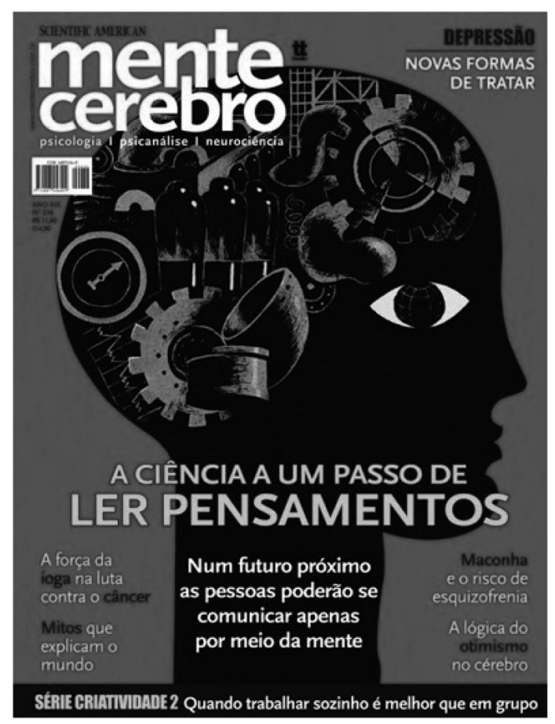

Figura 1. Revista mente e cérebro, set. 2012, ed. 236: A ciência a um passo de ler pensamentos.

A revista apresenta, em sua capa, um esboço de cabeça conectada com tubos, engrenagens, relógios e outros mecanismos, em tons cinza, que ocupam considerável espaço proporcional do cérebro. A composição dessas "peças", tanto em seu formato, quanto na disposição na qual foram organizadas, remete às rugosidades da superfície do cérebro.

Identificamos como mensagem retórica nessa capa que o cérebro é um receptor/emissor de sinais que pode funcionar como transmissor de dados. Percebemos que, na capa, insinua-se a prerrogativa da ciência como "avalizadora" do modelo apresentado, em que o pensamento seria 
fruto de organização biomecânica, sendo passível de intervenção técnica, podendo ser modalizado como aparato eletrônico de comunicação.

Reforça-se aqui, pensamos, a ideia do cérebro como entidade maquínica, que interfere - ou mesmo gera - o pensamento em sua imaterialidade, isolando-se, assim, os aspectos subjetivos do humano, fazendo emergir apenas elementos biomecânicos no funcionamento do órgão. Ao cabo, demarca-se sutilmente a presença do cérebro ("órgão") como uma "central", em que o pensamento (abstrato) é processado, ressaltando-se a hipótese da relevância do órgão sobre outras formas de apreensão da vida.

Cabe observar que essa reflexão não teria sentido, se a análise das capas fosse apenas textual, uma vez que não há referência ao cérebro na manchete, ou em seu complemento. Nas imagens apresentadas, por sua vez, não há uma correlação imediata com elementos imateriais (pensamentos). É na simbiose de palavra e imagem que é possível perceber a mensagem retórica, que apreende uma temática comum nas neurociências.

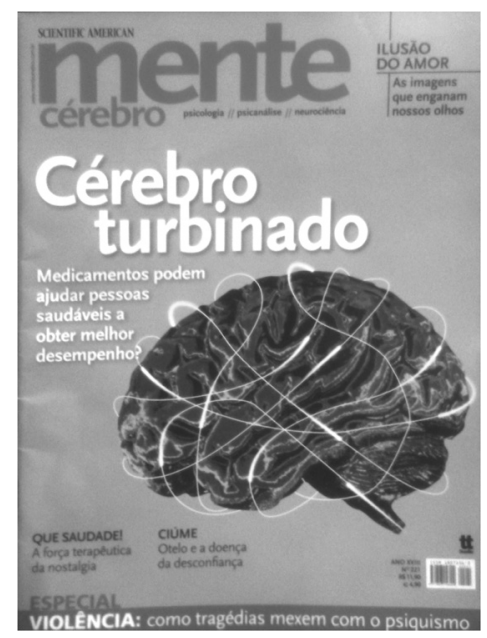

Figura 2. Revista Mente e Cérebro, jun. 2011, ed. 221, "Cérebro Turbinado". 
Na edição 221, de junho de 2011, o título é: Cérebro Turbinado: Medicamentos podem ajudar pessoas saudáveis a obter melhor desempenho? Na capa, o órgão é tratado a partir da proposta de medicamentos que podem potencializar sua performance (figura 2). No lugar de veias e sangues, as rugosidades são preenchidas por cores lembrando os exames de tomografia computadorizada, referindo-se a diferentes regiões do cérebro sendo ativadas. O próprio contorno do órgão é circundado por linhas brancas que insinuam fios/circuitos eletrônicos, sugerindo intensa atividade neuronal, reforçado por áreas mais largas, onde esse movimento elétrico seria mais intenso.

O termo "turbinado" já sugere uma qualificação quanto ao desempenho do cérebro, confirmando a analogia com componentes eletrônicos em busca por melhor desempenho. O cérebro pode ter, portanto, sua atividade qualificada pelos medicamentos, como aditivo para uma máquina que conquista força superior, ao se equiparar aos superpoderes das máquinas.

A edição 235 (agosto/2012), teve como tema: Criatividade: É possível exercitar o potencial para ter boas ideias e encontrar soluções com mais facilidade (figura 3). 


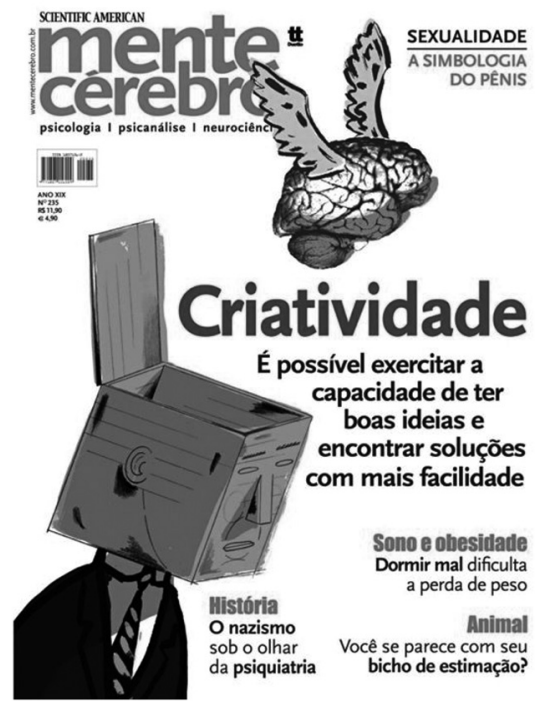

Figura 3. Revista Mente e Cérebro, ago. 2012, ed. 235: "Criatividade".

A capa mostra um cérebro alado, saindo da cabeça do personagem, com forte expressão de preocupação. A concepção emergente da mensagem retórica é a de ver o problema de crise na produção de boas ideias como uma "fuga" do cérebro, como se o órgão saísse da "caixa" (expressão popular usada para a criatividade, "pensar fora da caixa"), levando embora o cérebro junto.

Mais uma vez é associada a temática subjetiva à analogia do localismo, o cérebro sendo pensado como centro do pensamento e das habilidades cognitivas. O desenho materializa a ideia de que a criatividade está no cérebro e sem ele, essa habilidade não pode ser executada.

Vale observar a fisionomia do personagem, que lembra um robô, um ser construído, resultado de objeto complexo organizado e como tal, sem 
capacidade de reação própria. Essa expressão reforça a ideia do sujeito como refém do estado de funcionamento de seu cérebro para realizar tarefas como criar.

Mais um caso emblemático foi o da capa de Mente e Cérebro de janeiro de 2015 (ed. 264), cujo título foi: Psicologia ajuda você a mudar hábitos e alcançar objetivos: Lidar com a ansiedade e aproveitar melhor o tempo aumenta chances de realizar seus desejos (figura 4).

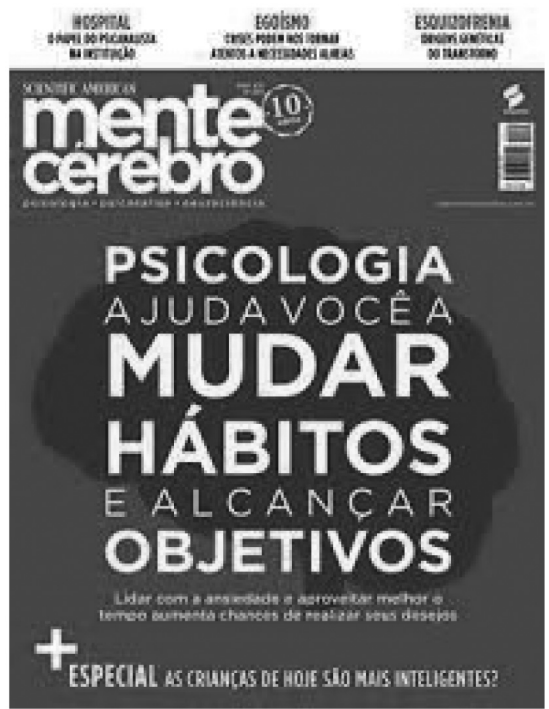

Figura 4. Revista Mente e Cérebro, jan. 2015, ed. 264: "Psicologia ajuda você a mudar hábitos". 
Apesar de o texto apresentar claramente que a abordagem se faz pelo viés das ciências humanas, a imagem de um cérebro vermelho, ao fundo, sugere ao nosso imaginário uma temática da psicologia no campo das biociências, com reconhecimento do cérebro como órgão de referência para a vida humana, em contraponto aos seus aspectos subjetivos e sociais.

A concepção que emerge da mensagem retórica é de que o cérebro pode ser modificado para se estabelecerem novos hábitos e se alcançarem objetivos. O cérebro pode ser o centro onde se "formatam" recursos para alcançar desejos, tal como é sugerido no texto da manchete. Ao final, não se supõe, na capa, o objeto da psicologia na mente ou nas questões humanas e sociais, mas no órgão cérebro, como resultado de sua funcionalidade.

A edição 247, de agosto de 2013, traz o cérebro figurando o centro de uma dor. A manchete "Alívio para a Enxaqueca: Pesquisas brasileiras com o hormônio do sono abrem caminho para compreender e tratar a dor que aflige mais de 20 milhões de pessoas no país. O desafio é lidar com seu principal gatilho: o estresse" (figura 5).

A capa aborda a busca por alívio para o problema da enxaqueca. É reforçada na capa, como meio para se estabelecer empatia com o leitor, a analogia com um cérebro "energizado", em alta tensão, chamando atenção para a enxaqueca, uma dor comum, que, no entanto, imobiliza muitos pacientes. 


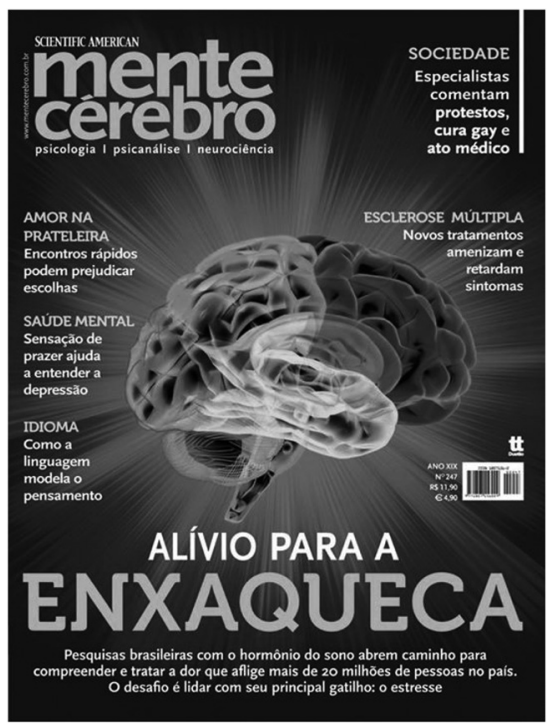

Figura 5. Revista Mente e Cérebro, edição 247, de agosto de 2013: "Alívio para enxaqueca".

A mensagem retórica que emerge desta capa é a do cérebro como o centro original da enxaqueca, como um mecanismo com altas descargas elétricas que geram o mal-estar. O cérebro é ilustrado como um terminal nervoso de energia, onde se desencadeia essa disfunção.

\section{Conclusão}

Ao final do processo de análise, percebemos, de imediato, a identificação de um aparente descompasso na intenção retórica entre texto e imagem, quando tomados em separado. O que confirma, a nosso ver, a hipótese de que é na simbiose entre imagem e palavra que o processo retórico de convencimento ganha força. Como vimos em alguns dos 
exemplos analisados, o texto parece remeter a uma abordagem pelas ciências humanas, porém a imagem correlacionada "amarra" a temática na perspectiva das biociências, tornando o cérebro-máquina o centro efetivo da abordagem, elevando-o a um patamar estratégico na representação social da saúde, da vida e do viver, em acordo com as hipóteses iniciais do presente estudo.

A simbiose retórica não se mostrou, dessa forma, no conjunto das capas pesquisadas, ocasional, pois embora as mensagens nelas sugeridas pareçam caminhar para sentidos opostos quanto aos elementos que deles emergem (imagem e texto), de fato seguem em direção a um mesmo conjunto de sentidos geralmente reiterados em outras capas, com a mesma mensagem.

Assim, se tomarmos como critério analítico uma única capa, como é frequente na análise tradicional de conteúdo, ou mesmo na análise semiótica, o efeito retórico ocasional não fica evidente. Ele só se constitui quando percebemos que essas mensagens estão em tensionamento constante ao longo de diferentes edições, em períodos de tempo variáveis, trazendo à tona a mesma intenção prescritiva que dispara o convencimento quanto à normatividade sobre a vida. Os padrões de abordagem se repetem em diversos momentos, caracterizando o esforço reiterado de geração de convencimento sobre modos específicos de abordar e conduzir vida e saúde.

A primeira constatação resultante da análise efetivada é o reforço na distinção entre cérebro e mente. Definitivamente, os dois termos não são encarados pelas revistas como tendo o mesmo sentido. Cérebro é o órgão físico, o hardware, o processador biológico; a mente, por sua vez, faz as vezes de software, responsável pela programação, pelo fluxo e desenvolvimento dos aspectos imateriais do órgão. O que nos leva a concluir que a mente, em muitos momentos, é abordada nesses periódicos 
como resultado da ação do cérebro, isto é, como efeito de sua fisiologia e de sua constituição sistêmica. Não são considerados outros aspectos, como a subjetividade do indivíduo ou as relações sociais. Mesmo o corpo é também muitas vezes tratado como subjugado em relação ao cérebro, como resultado de estruturas neuronais no comando dos órgãos, e como local onde se originam as diversas patologias devido ao seu mau funcionamento.

Na construção gráfica das capas, observamos, em diversos momentos, a existência de uma reprodução de elementos característicos dos aparatos tecnológicos, que vem ganhando a cada dia mais espaço na sociedade contemporânea. Há referência ao cérebro como circuito eletrônico, com descargas elétricas, identificando o seu formato e funcionamento às redes de energia ou a chips eletrônicos.

Um órgão que, muitas vezes, aparece isolado, recortado e destacado em cores, luzes e formatos, tomando o lugar do corpo biológico, e mesmo do sujeito individual, sustentado apenas por uma cabeça transparente, que serve mais de suporte desse núcleo onde ocorre a vida, do que como um meio de expressão de suas ações. Este cérebro ágil, potente e decidido, aparece retoricamente como capaz de manter as raízes e os comandos que justificam todos os jogos simbólicos da mente.

O corpo, em muitos casos, é também "transparente", com a aparência de vidro. As feições são de bonecos com proporções perfeitas, sem expressões de sentimento. Tudo está neutralizado, apenas o cérebro brilha, e tem sua atividade intensa marcada por cores, luzes e descargas elétricas. O próprio cérebro não se apresenta desnudado, está sempre travestido de cores, de formas e alusões que o afastam de um cérebro "natural", isto é, biológico. Visualmente aproxima-se mais de um computador com modelo atualizado, potente, eficiente e preciso, do que de um órgão frágil, que depende do resto do corpo para contê-lo e mantê-lo vivo. 
Cabe salientar, neste momento, que a pesquisa fez vir à tona, na análise, a ausência de uma perspectiva oposta à vida. A morte não aparece figurada, nem mencionada. O contrário da vida, como pensou Canguilhem (2012) não é a morte, mas a ausência ou falha da vida em seu funcionamento pleno, aquilo que nos afasta da perfeição, conforme apontado no projeto identificado por Sfez (1996).

A relação com a máquina cabe bem neste propósito, pois, tal qual acontece na tecnologia contemporânea, um corpo sem plenas condições de funcionamento é considerado sucata e precisa ser trocado; ele deixa de ser máquina para servir de suplemento de reposição para outra máquina em melhores condições.

A representação social que emerge das imagens veiculadas do cérebro se constitui como sedutora, por traduzir, em doses homeopáticas, uma representação do mesmo como órgão pelo qual passam as questões mais relevantes para o funcionamento da vida. Seu efeito, ainda que não perceptível numa única exposição, numa capa específica, pode ser verificado ao longo de uma série histórica e em seu cruzamento com outras abordagens em diferentes publicações, como verificaram Luz et al. (2013a), na contiguidade de sentidos que emergem das capas que compõem a vitrine das bancas. Essa representação social acaba por constituir-se em um modo socialmente compartilhado de sentidos atribuídos a esse órgão, ajudando a construir o imaginário específico do mesmo.

Precisamos demarcar ainda, com ênfase, que não estamos afirmando que ocorre um efeito de completo convencimento social. Primeiro, porque a retórica não se propõe a constranger ou intimidar o leitor/espectador, mas a sensibilizá-lo, racional e emocionalmente, para que este se convença da veracidade da mensagem emitida pelo interlocutor. Segundo, porque esse leitor não consegue absorver integralmente o comando direcionado pelas mensagens, criando tensionamentos e resistências 
como resposta ao poder simbólico dos dispositivos de verdades (Foucault, 2000; Bourdieu, 2010).

De qualquer forma, mesmo que se oponha ao sugestionamento, o leitor compartilha do mesmo repertório de mensagens e imagens comuns na sociedade em que está inserido, partilhando de elementos simbólicos que alimentam o imaginário dos grupos em que está inserido.

Pudemos observar, durante o processo analítico, o fortalecimento da representação do cérebro para a sociedade como um todo, estando esse órgão sujeito à contínua medicalização, possivelmente superior a de outros órgãos e funções biológicas, em detrimento de abordagens alternativas de terapêuticas destinadas ao corpo e suas funções vitais, biológicas ou psicológicas.

Entendemos que é possível ampliar essa análise para outros elementos simbólicos que possam descrever os modos de produção de "imagens" da saúde e da vida na sociedade contemporânea. As mensagens disseminadas são sutis, com carga retórica constante, muitas vezes contundentes. Tal como identificamos no cérebro da revista Mente e Cérebro, apresentam-se, nas mensagens, achados incontestáveis da produção de cuidado do mesmo pelas Biociências que, através de estratégia retórica, buscam ignorar, ou mesmo excluir, perspectivas alternativas de compreensão e de atenção sobre a vida e o viver não condizentes com as proposições do atual paradigma biomédico.

Anderson dos Santos Machado é doutorando em Comunicação (PUCRS), mestre em Saúde Coletiva (UFRGS), bacharel em Comunicação Social (UFSM), especialista em Comunicação em Saúde (Unisinos/ESPRS).

>andersonsmachado@yahoo.com.br 
Madel Therezinha Luz é professora do Programa de Pós-Graduação em Saúde Coletiva da Universidade Federal do Rio Grande do Sul (PGCOL/UFRGS) e líder do Grupo CNPq Racionalidades em Saúde: Sistemas Médicos Complexos e Práticas Complementares e Integrativas. $\measuredangle$ madelluzz@gmail.com

\section{Referências}

1. AKERMAN, M.; FEUERWERKER, L. Estou me formando (ou eu me formei) e quero trabalhar, que oportunidades o sistema de saúde me oferece na saúde coletiva? Onde eu posso atuar e que competências preciso desenvolver?. In: CAMPOS, G. W. S. (org.). Tratado de Saúde Coletiva. 2 ed. São Paulo: Hucitec, 2012. p. 171-88.

2. BAUMAN, Z. Modernidade Líquida. Rio de Janeiro: Jorge Zahar, 2001.

3. BOURDIEU, P. O Poder Simbólico. Rio de Janeiro: Bertrand Brasil, 2010.

4. CANGUILHEM, G. Normal e patológico. In: CANGUILHEM, G. Conhecimento da vida. Rio de Janeiro: Forense Universitária, 2012.

5. CASTIEL, L. D. Insegurança, ética e comunicação em saúde. Saúde Pública, v. 37, n. 2, p. 161-7, 2003.

6. CECCIM, R. B. et al. Educação e Saúde: ensino e cidadania como travessia de fronteira. Trabalho, Educação e Saúde. Rio de Janeiro, v.6, n.3, p.443-456, nov. 2008/fev. 2009.

7. DURAND, G. A imaginação simbólica. Lisboa: Edições 70, 1993.

8. FOUCAULT, M. Microfísica do poder. Rio de Janeiro: Graal, 2000.

9. FOUCAULT, M. Resumo dos Cursos do Collège de France (1970-1982). Rio de Janeiro: Jorge Zahar, 1997.

10. KICKHÖFEL, E. As neurociências: questões filosóficas. São Paulo: WMF Martins Fontes, 2014.

11. LUZ, M. T. Natural, Racional, Social: Razão Médica e Racionalidade Científica Moderna. 2 ed. São Paulo: Hucitec, 2004.

12. LUZ, M. T. O Impacto da Epidemia de HIV/AIDS nas Representações Sociais. Saúde, Sexo e Educação, Rio de Janeiro, v. VI, n. 13, p. 6-11, 1998.

13. LUZ, M. T. Pequenas Destruições, Danos Irreparáveis: Comentários aos Modos Sociais de Vida no Capitalismo Pós-Moderno; Implicações na Saúde. Rio de Janeiro: Epos, Vol.4, no 2, 2013. 
14. LUZ, M. T. et al. Contribuição ao estudo do imaginário social contemporâneo: retórica e imagens das biociências em periódicos de divulgação científica. Interfaces, v.17, n.47, p. 901-12, out./dez. 2013a.

15. LUZ, M. T. et al. A ciência como cultura no mundo contemporâneo: divulgação midiática de saberes científicos e construção do imaginário social. Projeto de Pesquisa submetido a Universidade Federal do Rio Grande do Sul, 2011.

16. LUZ, M. T. et al. A Ciência como cultura do mundo contemporâneo: a utopia dos saberes das biociências e a construção midiática do imaginário social. Sociologias, v. 15, n. 32, p. 236-54, 2013b.

17. MAFFESOLI, M. O imaginário é uma realidade. Famecos, v.1, n.15, p.74-81, 2001.

18. MEDRADO, B. Textos em cena: a mídia como prática discursiva. In: SPINK, M.J. (Org.). Práticas discursivas e produção de sentidos no cotidiano. 2 ed. São Paulo: Cortez, 2000. p.243-71.

19. MELLO, G. Revista Mente e Cérebro: A midiatização do discurso médico. Monografia de Conclusão de Curso. Santa Maria: Unifra, 2010.

20. MERTON, Robert. The Sociology of Science: Theoretical and empirical investigations. Chicago: Chicago University Press, 1973.

21. MORAES, A. F. Informação Estratégica para as Ações de Intervenção Social na Saúde. Ciências Saúde Coletiva, Rio de Janeiro, v. 13, supl. 2, p. 2041-8, 2008.

22. ORTEGA, F. O sujeito cerebral e o movimento da neurodiversidade. Mana, Rio de Janeiro, v. 14, n. 2, out. 2008.

23. ORTEGA, F. Elementos para uma história da neuroascese. Hist. cienc. Saúde - Manguinhos, Rio de Janeiro, v. 16, n. 3, set. 2009.

24. ORTEGA, F.; ZORZANELLI, R. Corpo em Evidência: a ciência e a redefinição do humano. Rio de Janeiro: Civilização Brasileira, 2010.

25. PINHEIRO, R.; MATTOS, R. A (org.). Construção da integralidade: cotidiano, saberes e práticas em saúde. 4 ed. Rio de Janeiro: IMS/UERJ - CEPESC ABRASCO, 2007.

26. SABINO, C. O Nascimento do bodybuilding. In: LUZ, M.T.; BARROS, N. F. (orgs.). Racionalidades Médicas e Práticas Integrativas de Saúde, Rio de Janeiro: UERJ/IMS/LAPPIS, 2012, p. 357-96.

27. SILVA, J. M. As tecnologias do Imaginário. 2 ed. Porto Alegre: Sulina, 2006.

28. SILVA, G. O Imaginário, o sensível e o jornalismo. In: CASTRO, G. de (org.). Mídia e Imaginário. São Paulo: Annablume, p. 93-111, 2012. 
29. SFEZ, Lucien. A saúde perfeita: crítica de uma nova utopia. 7ạ edição. São Paulo: Edições Loyola, 1996.

30. SPINK, M. J. Representações Sociais: Questionando o Estado da Arte. Psicologia e Sociedade, São Paulo, v. 8, n. 2, jul./dez. 1996, p. 166-86.

31. WEBER, Max. A Ética Protestante e o Espírito do Capitalismo. São Paulo: Companhia das Letras, 2004. 335 p.

Recebido: 03.12.2015 Aceito: 10.05.2017 